\title{
Thyroglossal Duct Anomalies in Pediatric and Adult Population: A 10-Year Experience in a Tertiary Care Hospital
}

\author{
Montasir Junaid1*, Ghaleb Al-Sayed"1, Sayed Agha Ali Shah' ${ }^{2}$, Hareem U. Khan ${ }^{3}$, \\ Ali Mahdi Al Qannass ${ }^{1}$, Nadeem W. Malik' ${ }^{1}$, Yahya Al Kahtani' ${ }^{1}$ Ahmed Arghabi', \\ Abdul Aziz Ali Binhossan', Sadaf Qadeer Ahmed" \\ ${ }^{1}$ Department of Otolaryngology-Head and Neck Surgery, Armed Forces Hospital, Khamis Mushait, KSA \\ ${ }^{2}$ Department of Pathology, Armed Forces Hospital, Khamis Mushait, KSA \\ ${ }^{3}$ Department of Otolaryngology-Head and Neck Surgery, Stanford University, Palo Alto, USA \\ ${ }^{4}$ Department of Otolaryngology-Head and Neck Surgery, Sir Syed University of Medical Sciences for Girls, Karachi, Pakistan \\ Email: ^montsj@gmail.com
}

How to cite this paper: Junaid, M. Al-Sayed, G., Shah, S.A.A., Khan, H.U., Al Qannass, A.M., Malik, N.W., Al Kahtani, Y., Arghabi, A., Binhossan, A.A.A. and Ahmed, S.Q. (2021) Thyroglossal Duct Anomalies in Pediatric and Adult Population: A 10-Year Experience in a Tertiary Care Hospital. Surgical Science, 12, 226-235. https://doi.org/10.4236/ss.2021.127025

Received: June 18, 2021

Accepted: July 23, 2021

Published: July 26, 2021

Copyright $\odot 2021$ by author(s) and Scientific Research Publishing Inc. This work is licensed under the Creative Commons Attribution International License (CC BY 4.0).

http://creativecommons.org/licenses/by/4.0/ (c) (i) Open Access

\begin{abstract}
Introduction: Thyroglossal duct cyst is a well-recognized congenital midline neck swelling observed in early childhood and rarely in adults. It may reveal itself as a painless cyst, abscess, or as fistula. Several studies have been conducted across the world, but the literature is scarce on its presentation and complications in the Middle East. This indexing study aims to report a 10-year experience with thyroglossal duct cyst (TGDC) presentation, excision, and recurrence at a teaching hospital in Saudi Arabia (KSA). Methods: A retrospective chart review was conducted at the Armed Forces Hospital Southern Region, KSA from December 2008 to December 2018. Data were retrieved from the electronic medical record system of the hospital and validated with the histopathology records. A total of 48 patients diagnosed as TGDC, sinus or fistula were identified. Stata ver. 16.1 was used to analyze the data and results formulated using regression model and Pearson's chi-square test. Results: The majority of our patients were female (60.4\%), and the most common presentation was a midline neck swelling which moved with tongue protrusion. Surgical excision via Complete Sistrunk procedure was the operation of choice in $60.5 \%$ followed by excision of the cyst with tract and sinus tract. Previous infection and surgical history contributed to complications in our patients, but no association of age or gender was observed. Patients presenting with infected and discharging cysts were found to be much more likely to develop a recurrence (9 patients). Cysts deep to the hyoid showed more recurrence $[\mathrm{n}=7(78 \%)]$ compared to superficial cysts $[\mathrm{n}=2(22 \%)]$ and posterior and multi-tract lesions also showed significant recurrence.
\end{abstract}


Conclusion: Despite being a common cause of neck swelling, thyroglossal duct cyst is often missed on physical exams. To reduce complications, timely diagnosis and treatment are necessary.

\section{Keywords}

Midline Neck Swelling, Thyroglossal Duct Cyst, Sinus Tract, Sistrunk Procedure

\section{Introduction}

Thyroglossal duct cyst (TGDC) is a well-documented, well-recognized congenital midline neck swelling, which may reveal itself as a painless cyst, abscess, or fistula. It is frequently observed in early childhood and rarely in adulthood [1].

The thyroglossal duct originates from the foramen caecum and runs inferiorly, adjacent to the hyoid bone, along the natural path of descent of the thyroid gland. It is the failure of the duct to obliterate at the $8^{\text {th }}$ week of gestation which leads to the formation of a cyst anywhere along its decent path. The other differentials included for such a swelling are dermoid cyst, branchial cyst, ectopic thyroid tissue, hemangioma, and neck lymph nodes [2]. Thyroglossal duct cyst has also been associated with median ectopic thyroid tissue, but only $1 \%$ or less of these have been associated with occult thyroid malignancy [3].

The typical patient presents in an outpatient setting with painless midline neck swelling, clinically palpated between hyoid and thyroid cartilage, moving with protrusion of the tongue [1] [2] [4]. Due to the high rate of infection in these cysts it is not uncommon $\left(1 / 3^{\text {rd }}\right)$ to find patients either with a history of prior infections or having one. [3]

The definitive treatment for thyroglossal duct cyst is complete surgical excision along with its tract (Sistrunk procedure) as described by W.E. Sistrunk [4] [5] in 1920. The procedure entails removal of cyst followed with excision of its tract up to hyoid bone and completed by removing a muscular cuff around tongue base (the embryologic pathway of descent) [5]. Though postoperative complications are rare, recurrence is a major unwarranted sequela of the surgical intervention [3].

Several studies have been conducted across the world, but the literature is scarce on its presentation and complications in the Middle East. The index study aims to report a 10-year experience with thyroglossal duct cyst presentation, excision, and recurrence at a teaching hospital in Saudi Arabia (KSA).

\section{Methodology}

A retrospective chart review was conducted after ethical approval from the institutional ethical committee at the Armed Forces Hospital Southern Region, KSA from December 2008 to December 2018. All patients presenting to pediatric 
surgery, general surgery and otolaryngology departments were included. All data was retrieved from the electronic medical record system of the hospital and validated with the histopathology departmental records. A total of 48 patients diagnosed as TGDC, sinus or fistula were identified. Patients with incomplete records were excluded.

A report form was drafted to record patient demographics, clinical presentation, physical examination findings, laboratory and radiological investigations, operative details and complications, recurrence, follow-up, and final histopathology findings. Patient demographics were tabulated. Stata version 16.1 was used to analyze the data and results formulated using regression model and Pearson's chi-square test.

\section{Results (Table 1)}

\section{History and clinical presentation:}

Of the 48 patients included in the study, all were Saudi nationals, 29 (60.4\%) were females and the mean age at presentation was $12.31 \pm 9.88$ years. The majority of the swelling/cysts were clinically palpated in the midline $(85.42 \%)$ and below the hyoid $(45.83 \%)$. Nine (9) patients presented to the clinic with actively infected swelling/cyst while 39 patients had no signs of clinically active infection. Out of 48 patients, 27 (56.3\%) patients had a previous history of infection (recurrent). Thirty-six (36) patients were surgery naïve and 12 (25\%) had a history of prior surgical intervention for central neck swelling (either excision of cyst and sinus tract (18.8\%) or incision and drainage of swelling (4.2\%) or Sistrunk procedure (2.1\%)).

Neck swelling demographics:

Infra-hyoid lesions were more prevalent $(\mathrm{n}=22$ or $45.8 \%)$ and the average diameter of the lesion was $2.35 \pm 0.95 \mathrm{~cm}$. Most of the lesions (79.2\%) were mobile upon tongue protrusion. Lesions were commonly observed in the midline (85.4\%) compared to lateral lesions.

Radiological intervention:

Ultrasound was the preferred imaging modality used in $32(66.7 \%)$ patients followed by CT head and neck in 15 (31.3\%).

\section{Surgical intervention:}

The otolaryngology, head, and neck surgery (ORL-HNS) department performed most $(60.42 \%)$ of the surgeries followed by General Surgery (27.08\%) and pediatric surgery $(12.50 \%)$ while Sistrunk (62.5\%) procedure remained the preferred way of excision. The typical procedure included standard midline skin crease incision, meticulous dissection around the cyst and its tract with the removal of the midline portion of hyoid and cuff of the surrounding base of tongue musculature. In 15 (31.25\%) patients the thyroglossal duct cyst was excised along with fistulous tract only while in three patients a complete cyst excision was performed, and no tract identified. Thyroglossal duct Cyst was identified to be superficial in $54.17 \%$ of cases while the sinus tract was found to be traversing deep to the hyoid bone in $60.42 \%$ of cases. 
Table 1. Details of the pertinent findings of the 48 patients presenting as suspected thyroglossal duct cyst and its management.

\begin{tabular}{|c|c|}
\hline Patient Demographics & 48 patients \\
\hline Nationality & Saudi nationals: 48 (100\%) \\
\hline Gender & $\begin{array}{c}\text { Males: } 19(39.6 \%) \\
\text { Females: } 29(60.4 \%)\end{array}$ \\
\hline Median age & $12.31 \pm 9.88$ years \\
\hline \multicolumn{2}{|l|}{ Clinical presentation } \\
\hline Infected swelling/cyst with discharge & $6(12.5 \%)$ \\
\hline Infected swelling/cyst without discharge & $3(6.3 \%)$ \\
\hline Swelling/cyst without infection & $24(50 \%)$ \\
\hline Discharging sinus without infection & $15(31.3 \%)$ \\
\hline \multicolumn{2}{|l|}{ Mobile with tongue protrusion } \\
\hline Yes & $38(79.17 \%)$ \\
\hline No & $10(20.83 \%)$ \\
\hline \multicolumn{2}{|c|}{ History of previous operation/Surgery for central neck swelling } \\
\hline Yes & $12(25 \%)$ \\
\hline No & $36(75 \%)$ \\
\hline \multicolumn{2}{|l|}{ Side of Lesion } \\
\hline Midline & $41(85.42 \%)$ \\
\hline Lateral & $7(14.59 \%)$ \\
\hline \multicolumn{2}{|c|}{ Location of the lesion at the time of clinical presentation } \\
\hline Below hyoid & $22(45.83 \%)$ \\
\hline Above hyoid & $10(20.83 \%)$ \\
\hline At the level of the hyoid & $16(33.33 \%)$ \\
\hline \multicolumn{2}{|l|}{ Method of excision } \\
\hline Complete Sistrunk & $30(62.5 \%)$ \\
\hline Excision of TGDC tract & $15(31.25 \%)$ \\
\hline Excision of Cyst without a tract & $3(6.25 \%)$ \\
\hline \multicolumn{2}{|l|}{ Location of cyst on the excision } \\
\hline Superficial to hyoid & $26(54.17 \%)$ \\
\hline Deep to hyoid & $22(45.83 \%)$ \\
\hline \multicolumn{2}{|l|}{ Sinus tract location } \\
\hline Posterior to hyoid & $29(60.42 \%)$ \\
\hline Anterior & $6(12.50 \%)$ \\
\hline Multi-tract & $9(18.75 \%)$ \\
\hline No tract identified & $4(8.33 \%)$ \\
\hline \multicolumn{2}{|l|}{ Post-operative complications } \\
\hline Nil & $37(77.1 \%)$ \\
\hline Recurrence & $9(18.8 \%)$ \\
\hline Hematoma & $2(4.2 \%)$ \\
\hline \multicolumn{2}{|l|}{ Surgical specialty } \\
\hline Otolaryngology head and neck surgery & $29(60.42 \%)$ \\
\hline General surgery & $13(27.08 \%)$ \\
\hline Pediatric surgery & $06(12.50 \%)$ \\
\hline
\end{tabular}




\section{Histopathology:}

All specimens were sent for histopathologic examination. Slides were stained with Hematoxylin and Eosin, Periodic acid Schiff and Alcian blue stains. Final Histopathology confirmed TGDC in all but two cases where it was found to be a dermoid cyst, but no malignancy was identified in any of the specimens. During histopathology evaluation, $45.8 \%$ of the cysts were lined by non-keratinized squamous epithelium and $35.4 \%$ by stratified columnar epithelium and $18.7 \%$ by pseudostratified ciliated columnar epithelium, while 19 (39.5\%) specimens showed the presence of thyroid follicles. Dermoid cysts contained sebaceous material and were lined by keratinized squamous epithelium with skin adnexa.

Post-operative course and complications:

Patients who presented with an infected cyst with discharge were more likely to have recurrence after surgery, but no correlation was found between the size, site or side of the cyst and recurrent cysts. A total of nine patients developed recurrent cysts after surgery at our hospital, of which $6(66 \%)$ were reoperated while $3(33 \%)$ decided to seek care elsewhere. No recurrence was identified in patients without any prior surgical intervention $(n=39,81.3 \%)$. Five $(55.6 \%)$ of the nine recurrent cases had a history of previous outside surgery, while four patients had been operated on at our institute earlier and all nine cases had a previous history of infection as well. Being infected at the time of surgery led to 4 (66\%) of the recurrent cases. Placement of drain had a positive association with recurrence and all 9 recurrent cases had drains placed in their surgery. Post-operative hematoma at the surgical site was identified in 2 cases (4.2\%) which was managed conservatively (aspiration and pressure dressing).

Hospital stays and post-operative follow-up:

Patients with shorter hospital stays ( $<24$ hours) fared better than the ones who stayed longer. $56.3 \%$ of patients were followed up to 16 months while $43.8 \%$ had a follow-up in outpatient clinics of less than 12 months.

\section{Discussion}

Thyroglossal duct anomaly is the most common congenital anomaly of the neck and the second most common neck mass found in children after inflammatory masses [4] [5] [6] [7]. Thyroglossal duct remnants occur in approximately 7\% of the population, and although the majority will remain asymptomatic, the index of suspicion should remain high until a final diagnosis of any neck mass is complete [8]. The majority (two-thirds) of patients with thyroglossal duct anomalies are diagnosed before 30 years of age, and more than half of these are identified before age of 10 years [9]. In our series, the mean age at the time of clinical presentation was found to be 12 years.

Patients present commonly with an asymptomatic, cystic neck mass in the midline or lateral neck, near the hyoid bone [10] [11]. The most common location for the cystic mass is adjacent to the hyoid bone, but it is not uncommon to find them between the tongue and hyoid bone, hyoid, and the 
pyramidal lobe, and within the tongue or the thyroid gland [11]. These neck masses will typically move with swallowing or protrusion of the tongue on examination since the TGDC is closely related to the foramen caecum and hyoid bone [1] [2]. A majority (79.17\%) of our patient's neck mass moved on tongue protrusion and were found adjacent to the hyoid bone in all cases.

Approximately one-third of thyroglossal duct cysts present with an active infection (common in adults) or a prior history of the same, while one-fourth of patients present with a draining sinus or a ruptured infected cyst. The cysts are usually infected via the mouth; thus, the most common organisms are Haemophilus influenzae, Staphylococcus aureus, and Staphylococcus epidermidis [11]. A significant (56.3\%) number of patients in our study had a prior history of infection in their TGDC while 9 patients had an ongoing cyst infection at the time of presentation in the out-patient clinic.

Thyroglossal duct cysts are lined with ductal epithelium or contain solid thyroid tissue (Figure 1 and Figure 2). While at times lining of the cysts cannot be identified because of repeated infections. The usual lining observed in these cysts is pseudostratified ciliated columnar epitheliums, non-keratinized squamous epithelium and stratified columnar epithelium with and without thyroid follicles which can be seen in $30 \%-60 \%$ of the cases [12]. In our study, the most common lining was non-keratinized squamous epithelium (45.8\%) and in $39.5 \%$ of the specimen, thyroid follicles were identified. Though the absence of thyroid follicles does not exclude TGDC. It is also important to exclude the differential diagnosis of the TGDC which includes branchial cleft cyst, dermoid and epidermoid cysts, laryngocele, thymic cysts, and lymphatic malformation [1]. In our study, two cases came out to be dermoid cysts. In general, all specimens should be sent for histopathologic examination as fewer than $1 \%$ will have malignant tissue, which is usually a well-differentiated thyroid papillary carcinoma [13]. In our study, none of the patients had any malignant changes on histopathology.

Preoperative imaging helps in diagnosis but is not mandatory since the clinical history and examination are revealing. However, ultrasonography is a safe and cost-effective method to distinguish between the cyst and thyroid swelling, without the need for radiation exposure and easily available at most of the centers. MRI and CT scans have been advocated as an adjuvant to the clinical diagnosis in complicated cases [6] [14] [15] [16] [17]. Our center relied on ultrasound of the neck to confirm diagnosis and CT was used in a handful of cases where recurrence was suspected (Figure 3).

The first detailed description for the complete removal of thyroglossal duct cyst was in 1893 by Schlange [3]. Later in 1920 W.E Sistrunk re-introduced the classic procedure and modified it in 1928 [4] [5]. To date, the Sistrunk procedure is the gold standard for the surgical removal of such cysts. When the Sistrunk procedure is performed in its entirety recurrence rates of less than $3 \%$ have been reported while the simple excision of thyroglossal duct cyst has high rates of about 55.6\% [6] [18]. However, other novel techniques for recurrent 


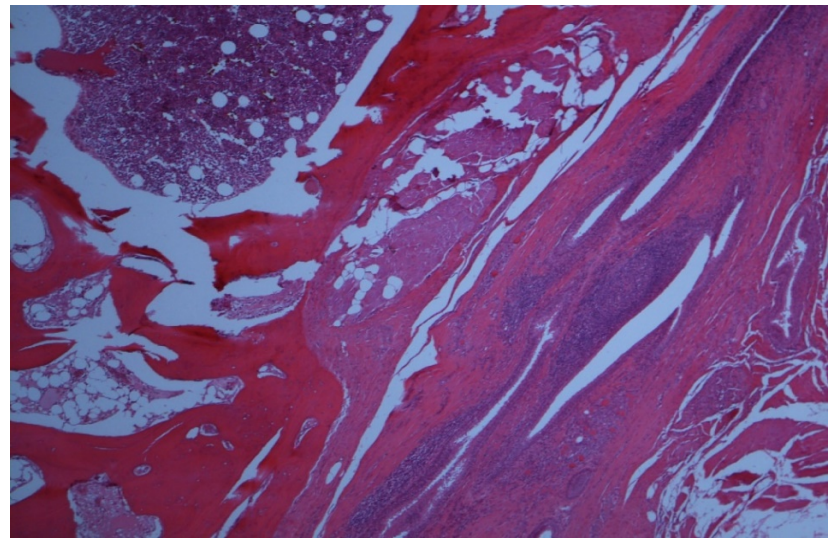

Figure 1 . The low power $(4 \times)$ section shows cysts lined with thyroid follicles and bone with marrow elements.

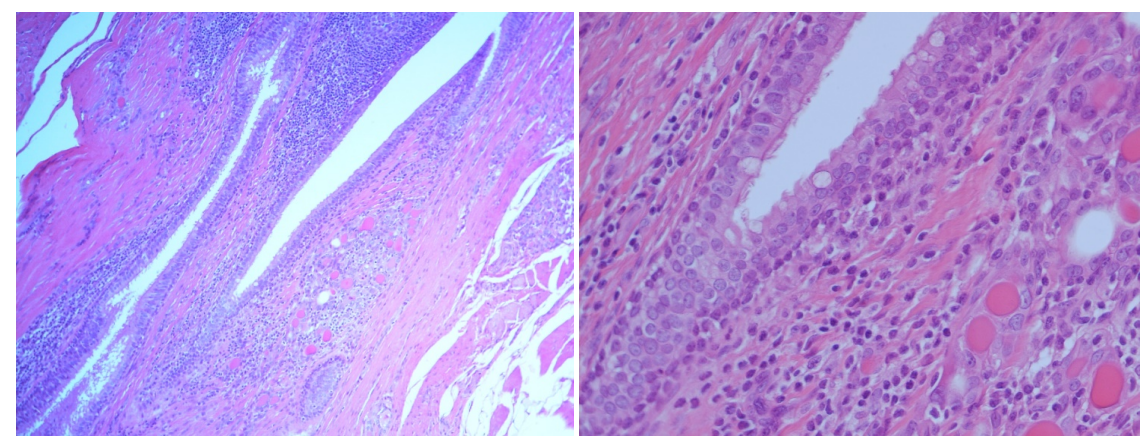

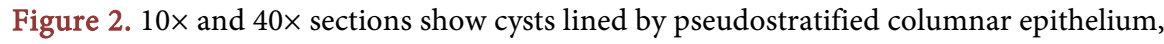
lymphoid tissue, and thyroid follicles.

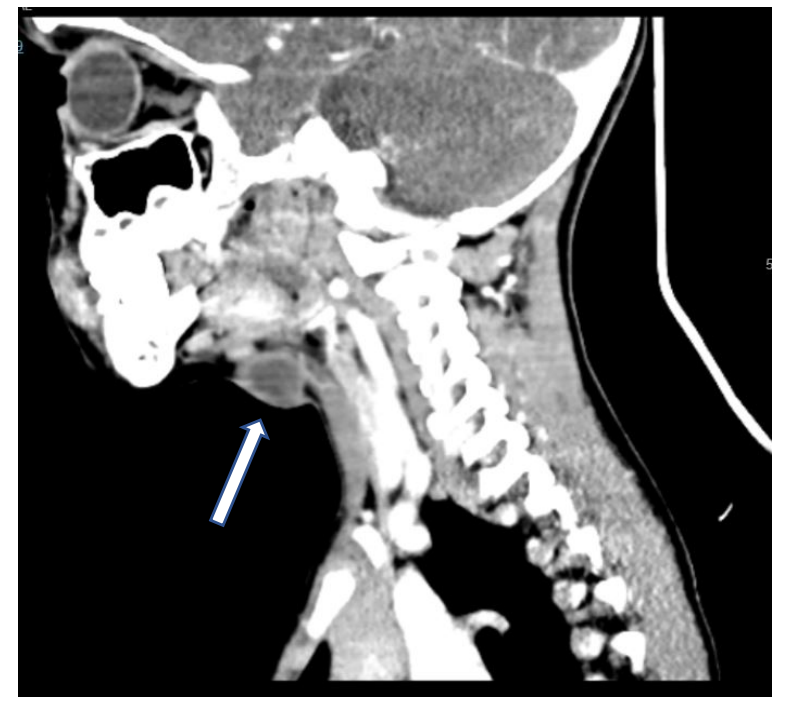

Figure 3. CT scan, sagittal view; recurrent thyroglossal duct cyst (white arrow) in an 8 -year-old child.

cases such as Suture-guided trans hyoid pharyngotomy by Perkins et al. [18] and Koempel'sf supra-hyoid technique [19] have been reported with promising results and need further exploration (Figure 4). 


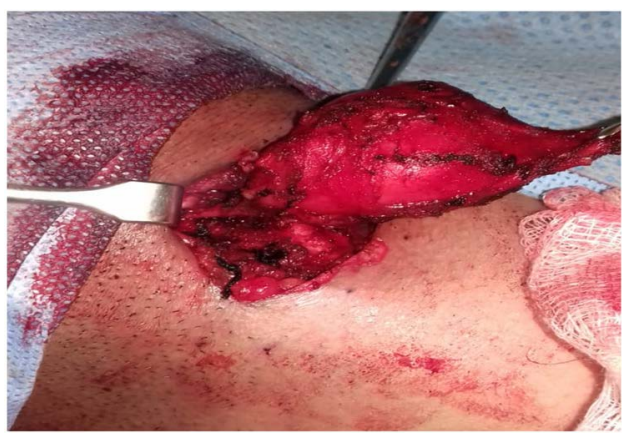

(A)

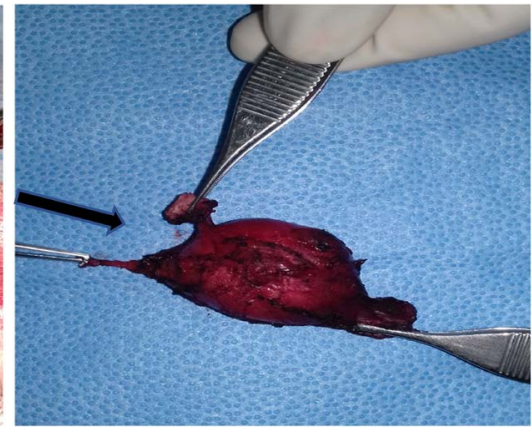

(B)

Figure 4. (A) Skin incision and thyroglossal duct cyst dissection; (B) Complete excision of thyroglossal duct cyst with its tract and hyoid bone (arrow in black).

The recurrence of thyroglossal duct cyst is not uncommon and is considered to be a major complication of this procedure. Factors associated with high recurrence are missed diagnosis, incomplete excision, or spill after cyst/duct rupture in the surgical field, multiple or posterior tracts, excision not extending beyond hyoid (not reaching tongue base) and history of recent infection or multiple infections before the surgery [1]. Other complications related to this procedure are usually local wound infections, hematoma, seroma formation and wound dehiscence [16]. Fistula formation can also occur but is rare as demonstrated by K.A Geller in their 20-year experience to be (2.9\%) in a series of 137 procedures [14].

In our series patients were admitted under 3 different specialties and the surgeon's prior experience and surgical expertise might differ from specialty to specialty. A significantly high number of recurrent infections (56.3\%) and prior surgical history in almost $1 / 3^{\text {rd }}$ cases made intra-operative identification of cyst tract more difficult for the surgeon and may have contributed to high recurrence rate in our patients (all 9 cases had a prior history of surgical intervention for TGDC), but no association of age or gender was observed. Patients presenting with infected and discharging cysts were found to be much more likely to develop recurrence. Cysts deep to the hyoid showed more recurrence $[\mathrm{n}=$ $7(78 \%)]$ compared to superficial cysts $[\mathrm{n}=2(22 \%]$ and posterior and multi-tract lesions also showed significant recurrence ( $44 \%$ each). In our experience, the recurrence rate was about $18 \%,(9 / 48)$ and even though Sistrunk was the dominant method of excision, our results showed no significant correlation between recurrence of TGDC and the method of excision.

There were limitations to our study which included a Single institute-based study, small sample size, retrospective review, and dependence on previous files/ charts with no long-term follow-up available. Further multi-center prospective studies are needed with longer follow-ups to overcome these limitations in the future. Despite these shortcomings, our study contributes to the existing literature and evidence-based practice of thyroglossal duct cyst management in our part of the world. 


\section{Conclusion}

Despite being a common cause of neck swelling, TGDC is often missed on physical exams. There is a great need to educate both the patient and surgeon for an earlier diagnosis to reduce chances of infection and hence the recurrence of TGDC. Recent infections and multiple surgeries in the past are associated with a high rate of recurrence.

\section{Conflicts of Interest}

The authors declare no conflicts of interest regarding the publication of this paper.

\section{References}

[1] Ibrahim, F.F., Alnoury, M.K., Varma, N., et al. (2015) Surgical Management Outcomes of Recurrent Thyroglossal Duct Cyst in Children-A Systematic Review. International Journal of Pediatric Otorhinolaryngology, 79, 863-867. https://doi.org/10.1016/j.ijporl.2015.03.019

[2] Hawkins, D.B., Jacoobson, B.E. and Klatt, E.C. (1982) Cysts of the Thyroglossal Duct. Laryngoscope, 92, 1254-1258. https://doi.org/10.1288/00005537-198211000-00006

[3] Harsha, W.J., Perkins, J.A., Lewis, C.W., et al. (2005) Head and Neck Endocrine Surgery in Children: 1997 and 2000. Archives of Otolaryngology-Head \& Neck Surgery, 131, 564-570. https://doi.org/10.1001/archotol.131.7.564

[4] Sistrunk, W.E. (1920) The Surgical Treatment of Cysts of the Thyroglossal Tract. Annals of Surgery, 71, 121-122. https://doi.org/10.1097/00000658-192002000-00002

[5] Sistrunk, W.E. (1928) Technique of Removal of Cysts and Sinuses of the Thyroglossal Duct. Surgery, Gynecology and Obstetrics, 46, 109-112.

[6] Rohof, D., Honings, J., Theunisse, et al. (2015) Recurrences after Thyroglossal Duct Cyst Surgery: Results in 207 Consecutive Cases and Review of the Literature. Head Neck, 37, 1699-1704. https://doi.org/10.1002/hed.23817

[7] Acierno, S.P. and Waldhausen, J.H. (2007) Congenital Cervical Cysts, Sinuses, and Fistulae. Otolaryngologic Clinics of North America, 40, 161-176. https://doi.org/10.1016/j.otc.2006.10.009

[8] Enepekides, D.J. (2001) Management of Congenital Anomalies of the Neck. Facial Plastic Surgery Clinics of North America, 9, 131-145.

[9] Mohan, P.S., Chokshi, R.A., Moser, R.L., et al. (2005) Thyroglossal Duct Cysts: A Consideration in Adults. The American Surgeon, 71, 508-511. https://doi.org/10.1177/000313480507100612

[10] Foley, D.S. and Fallat, M.E. (2006) Thyroglossal Duct and Other Congenital Midline Cervical Anomalies. Seminars in Pediatric Surgery, 15, 70-75.

https://doi.org/10.1053/j.sempedsurg.2006.02.003

[11] Ostlie, D.J., Burjonrappa, S.C., Snyder, C.L., et al. (2004) Thyroglossal Duct Infections and Surgical Outcomes. Journal of Pediatric Surgery, 39, 396-399. https://doi.org/10.1016/j.jpedsurg.2003.11.013

[12] Sprinzl, G.M., Koebke, J., Eckel, H.E., Wimmers-Klick, J. and Thumfart, W.F. (2000) Morphology of the Human Thyroglossal Tract: A Histologic and Macroscopic Study in Infants and Children. Annals of Otology, Rhinology \& Laryngology, 109, 1135-1139. 
https://doi.org/10.1177/000348940010901210

[13] Thompson, L.D.R., Herrera, H.B. and Lau, S.K. (2017) Thyroglossal Duct Cyst Carcinomas: A Clinicopathologic Series of 22 Cases with Staging Recommendations. Head and Neck Pathology, 11, 175-185. https://doi.org/10.1007/s12105-016-0757-y

[14] Geller, K.A., Cohen, D. and Koempel, J.A. (2014) Thyroglossal Duct Cyst and Sinuses: A 20-Year Los Angeles Experience and Lessons Learned. International Journal of Pediatric Otorhinolaryngology, 78, 264-267. https://doi.org/10.1016/j.ijporl.2013.11.018

[15] Zhang, L.C., Zhang, T.Y., Sha, Y., et al. (2011) Thyroglossal Duct Cyst with Recurrence after Cystectomy or Marsupialization under Endoscopy. Laryngoscope, 121, 1888-1892. https://doi.org/10.1002/lary.21909

[16] Saman, S., Ikram, M., Awan, M.S., et al. (2017) A Decade of Experience of Management of Thyroglossal Duct Cyst in a Tertiary Care Hospital: Differentiation between Children and Adults. The Indian Journal of Otolaryngology and Head \& Neck Surgery, 69, 97-101. https://doi.org/10.1007/s12070-016-1037-6

[17] Al-Thani, H., El-Menyar, A., Al-Sulaiti, M., et al. (2016) Presentation, Management, and Outcome of Thyroglossal Duct Cysts in Adult and Pediatric Populations: A 14-Year Single-Center Experience. Oman Medical Journal, 31, 276-283. https://doi.org/10.5001/omj.2016.54

[18] Perkins, J.A., Inglis, A.F., Sie, K.C., et al. (2006) Recurrent Thyroglossal Duct Cysts: A 23-Year Experience and a New Method for Management. Annals of Otology, Rhinology \& Laryngology, 115, 850-856. https://doi.org/10.1177/000348940611501110

[19] Koempel, J.A. (2014) Thyroglossal Duct Remnant Surgery: A Reliable, Reproducible Approach to the Suprahyoid Region. International Journal of Pediatric Otorhinolaryngology, 78, 1877-1882.

https://doi.org/10.1016/j.ijporl.2014.08.016 